\title{
Langmuir-Blodgett films of Nafion-nitrogen Doped Carbon Nanotubes as New Sensing Materials for the Determination of Caffeine in Tea
}

\author{
Yanju Wu ${ }^{1, *}$, Jianyao Kou ${ }^{1}$, Lijie Wang ${ }^{1}$, Long Cheng ${ }^{1}, K_{\text {Kui Lu }}^{2, *}$ \\ ${ }^{1}$ Department of Material and Chemistry Engineering, Henan University of Engineering, Zhengzhou, \\ 450007, P R China \\ ${ }^{2}$ School of Chemical Engineering and Food Science, Zhengzhou Institute of Technology, Zhengzhou, \\ 450044, P R China \\ *E-mail: yjwu2008@163.com (Dr. Yanju Wu) or luckyluke@ haue.edu.cn (Prof. Kui Lu)
}

doi: $10.20964 / 2019.12 .50$

Received: 17 April 2019 / Accepted: 9 September 2019 / Published: 29 October 2019

\begin{abstract}
In this work, Langmuir-Blodgett (LB) technique was proposed to fabricate the homogeneous and controlled films of Nafion-nitrogen doped carbon nanotubes (Nafion-NCNTs). Microstructure and electrochemical performance of LB films of Nafion-NCNTs was characterized by atomic force microscopy (AFM) images, scanning electron microscopy (SEM) images and electrochemical experiments. Moreover, the LB film of Nafion-NCNTs was transferred to the surface of glassy carbon (GC) electrode to fabricate the electrochemical sensor to apply for determination of caffeine. Electrochemical experiments show that the LB films of Nafion-NCNTs modified GC electrode can effectively increase electrochemical response of caffeine. Under the optimum conditions, the oxidation peak current of caffeine was proportional to its concentration in the range of $8.0 \times 10^{-8} \sim 4.0 \times 10^{-6} \mathrm{~mol}$ $\mathrm{L}^{-1}$, with a detection limit of $2.0 \times 10^{-8} \mathrm{~mol} \mathrm{~L}^{-1}$. And the modified GC electrode showed excellent selectivity, good stability and repeatability. It also was successfully used for determination of the content of caffeine in tea samples.
\end{abstract}

Keywords: Langmuir-Blodgett; Nafion-nitrogen doped carbon nanotubes; Caffeine; Square wave voltammetry

\section{FULL TEXT}

(C) 2019 The Authors. Published by ESG (www.electrochemsci.org). This article is an open access article distributed under the terms and conditions of the Creative Commons Attribution license (http://creativecommons.org/licenses/by/4.0/). 